\title{
História de um ensaio
}

\author{
Augusto MASSI* \\ Universidade de São Paulo (USP)
}

RESUMO: Este artigo investiga o papel da fotografia na poética de Max Martins (1926-2009) e, de forma mais detida, no livro Para ter onde ir (1992). Depois de realizar uma detalhada análise da foto de capa, passa a discutir tanto os seus diálogos como seus desdobramentos com a sequência de sete fotos distribuídas ao longo do volume. Consta no corpo do texto uma série de informações levantadas sobre os bastidores deste ensaio fotográfico produzido em Viena, pelo fotógrafo austríaco Béla Barsodi (1966), sob a direção artística do poeta paraense Age de Carvalho (1958). Ao final, destaca a centralidade da fotografia e da caligrafia na construção da identidade do Max Martins.

PALAVRAS-CHAVE: Fotografia. Max Martins. Projeto gráfico. Age de Carvalho.

Recebido em 13 de dezembro de 2016. Aprovado em 15 de dezembro de 2016.

\footnotetext{
* Augusto Massi é professor de Literatura Brasileira na Universidade de São Paulo. E-mail: amassi@usp.br.
} 
Max Martins está perfeitamente integrado à floresta. A figura humana se harmoniza e se incorpora à paisagem. Cultura e natureza convivem no mesmo espaço. Não há diferença entre plano e fundo. A imagem é fértil, potente e frondosa. Ela ultrapassa a capa do livro. A percepção inicial é de que o imaginário se expande e fulgura além do nosso campo de visão. A foto nos remete ao título: Para ter onde ir. Estamos no limiar: penetrar mata adentro ou se projetar mundo afora.

A textura da folhagem confunde o olho. As nervuras das folhas se misturam às rugas do rosto, as ramificações na superfície de cada folíolo se assemelham às veias nodosas das mãos, as zonas de sombra das árvores se entrelaçam na malha escura vestida pelo poeta. Num contraponto ao movimento geral de irradiação e expansão, o rosto e as mãos de Max, simetricamente alinhados, parecem suspensos como dois frutos luminosos na estufa da foto. Teatro de sombras.

$\mathrm{O}$ retrato camufla movimentos de eterno retorno. O mundo circula silencioso pelo tronco e pelas mãos que discretamente se cumprimentam, como se o duplo do poeta, pulsão de morte e pulsão de vida, pudesse reatar, reencontrar uma serenidade perdida. O gesto sugere tanto a posição de repouso de um morto no caixão como a meditação de um mestre zen.

\section{2.}

Assim que abrimos o livro, nos deparamos com um novo retrato do poeta, posicionado exatamente no mesmo cenário. Agora ele se curva diante do leitor, num gesto de grande humildade e despojamento, como quem nos convida para entrar em sua casa. Há nesta postura corporal algo de cerimonioso e sagrado.

A disposição simétrica das fotos sugere uma passagem da imobilidade para a animação, ilusão do movimento, primórdios da sequência cinematográfica. Essa percepção se acentua ainda mais quando outras fotos, intercaladas entre os poemas, realizam uma autêntica découpage. Do plano médio passamos para o plano de detalhe. O novo conjunto de fotos mostra uma redução violenta do enquadramento: capta parcelas mínimas das mãos e da cabeça de Max. O corte é tão radical que já não podemos ver os olhos do poeta. A cabeça baixa, esquiva e errante, só deixa à mostra os cabelos grisalhos e a testa franzida num diálogo cego com a ponta dos dedos, criando 
uma atmosfera meditativa. A foto que fecha o livro é, simultaneamente, ponto final e fruto enigmático.

Esse diálogo intenso entre fotografia e cinema não impede que outras relações estéticas se insinuem no interior do livro. Pelo contrário, várias sugestões de leitura convivem no mesmo habitat, prolongando os ritmos do mundo natural. Folhear o livro reaviva antigas sensações: ao adentrar na mata fechada abrimos caminho afastando os galhos com as mãos, sentimos o vento balançando a copa das árvores. Por isso, as fotos do rosto e das mãos funcionam como uma bússola que aponta incessantemente para o meridiano magnético da poesia.

\section{3.}

Intrigado com a força e beleza dessas fotos, na última vez que encontrei o poeta e amigo Age de Carvalho perguntei sobre o processo de criação desse ensaio fotográfico. A narrativa dos fatos me pareceu tão saborosa e as revelações tão surpreendentes que prometi escrever um ensaio a respeito.

Antes de entrar propriamente nos bastidores do relato, Age de Carvalho relembrou a sua motivação inicial: "Em 1990, Max foi meu hóspede por seis meses e aproveitei para finalmente realizar uma sessão de fotos com um mínimo de produção profissional. Fiz a direção de fotografia desse ensaio para ilustrar as capas de Para ter onde ir e Não para consolar, ambos de 1992".

A julgar pelo resultado final, o objetivo foi amplamente alcançado e os dois livros se beneficiaram do projeto gráfico assinado por Age de Carvalho. Passados tantos anos, é cada vez mais visível que a energia vital dessas fotos estava voltada para reforçar a presença física e poética de Max Martins, conferindo-lhe uma identidade própria e extremamente singular dentro da cena poética brasileira.

Este ensaio fotográfico, 47 fotos, foi realizado no Jardim Botânico de Viena, por um jovem fotógrafo austríaco, Béla Borsodi [1966], hoje um renomado profissional da fotografia de moda com trabalhos estampados na Vogue e Wallpaper.

O primeiro passo foi cortar o cabelo de Max. Por conta disso, ele guarda certa semelhança com Samuel Beckett. O rosto eivado, erodido, escavado. A cabeça toda grisalha, os cabelos levemente eriçados, um ar entre serenado e melancólico. Um detalhe interessante, segundo Age de Carvalho, é que, "terminada praticamente a 
sessão, Béla começou a fotografar os cabelos do Max em close-up, essa foi uma ideia dele - e que aproveitei mais tarde no miolo do livro".

O segundo foi a escolha do cenário. As fotos foram tiradas no Jardim Botânico de Viena. As folhas são de uma castanheira ornamental, muito comum na Europa Central, que dá esse fruto não comestível, cuja casca lembra tanto a nossa mamona como também um ouriço.

$\mathrm{O}$ terceiro foi o figurino. O pulôver preto que Max está vestindo pertencia à então esposa de Age de Carvalho, Martina de Carvalho-Hutter. Como durante a sessão a temperatura baixou, foi preciso improvisar e encontrar uma solução. Max ficou feliz com o empréstimo. Além disso, a malha escura lhe deu a aparência de um velho bardo, portador de uma experiência e de uma sabedoria.

Não deixa de ser curioso pensar que a força dessas fotos reside no que costumamos chamar de verdade, de autenticidade, de real. É quase impossível não achar certa graça na errância que presidiu este ensaio: o fotógrafo não era seu amigo, nem era seu leitor, sequer falava a língua do poeta; Viena nunca foi a sua cidade natal e mesmo aquelas castanheiras não eram de Belém do Pará; até mesmo a roupa que vestia não era de Max. No entanto, essas fotos continuam a revelar uma verdade muito próxima, quase íntima, aderente a sua personalidade poética: o estranho é familiar.

\section{4.}

Belém é hoje um dos principais centros da fotografia brasileira. E parte desta vitalidade teve início em 1980, com uma série de iniciativas que colocaram a cidade no mapa, entre elas, a "Foto Pará 82 - I Mostra Paraense de Fotografia" e a criação do FotoAtiva (1983), cujas oficinas, dirigidas pelo fotógrafo paulista Miguel Chikaoka, estimulou e formou várias gerações de fotógrafos. De lá para cá, além de Luiz Braga, Flavya Mutran, Pedro Paulo Góes Condurú e Octavio Cardoso [que fotografou Max Martins em Mosqueiro], muitos outros nomes foram se firmando, enriquecendo a cena atual.

Penso que essa forte cultura visual possa ter tido alguma influência na concepção gráfica de A fala entre parêntesis [1982], obra contemporânea desta efervescência em torno da fotografia. Muito embora Age de Carvalho pondere que "o projeto era apenas meu e do Max, não envolvia o Ronaldo Moraes Rêgo, que só chegou para participar quando o livro já estava terminado", a verdade é que as fotos 
potencializam o imaginário dos poemas. Por outro lado, é importante frisar que a marca do poeta-designer está sempre presente na edição das imagens: "aquela ideia das fotos para a capa e contracapa é minha: o Max de frente, eu de costas; e vice-versa".

Ronaldo Moraes Rêgo (hoje vinculado a arte da gravura) registra uma Belém em ruínas, e sob o signo da errância percorre terrenos baldios e fábricas abandonadas, seja no bairro do Reduto, nos arredores da Doca de Souza Franco ou na estrada do Mosqueiro. O contraponto com as fotos de Béla Borsodi é revelador. Sem que o retratado saía do lugar, elas nos transmitem uma sensação de intensa mobilidade, em perfeita sintonia com I Ching - o livro das mutações, leitura que orienta a escrita de Max.

Desde A fala entre parêntesis, renga escrita com Age de Carvalho, a caligrafia (mão) e a fotografia (rosto) participam intensamente do trabalho poético de Max Martins. Diria que lhe conferem uma identidade: matéria e forma. O ponto extremo desta fusão está na sua assinatura, sob a forma de um ideograma, estampada na capa dos Poemas reunidos [1952-2001], ideia presente no poema "Página do rosto" que fecha Caminho de Marahu [1983].

Age teve, e ainda tem, um papel decisivo no sentido de conferir identidade gráfica aos livros de Max. E, à medida que o tempo passa, aquele ensaio fotográfico de Béla Bosordi, realizado há quase trinta anos, vai adquirindo uma dimensão simbólica. Longe de se constituir numa escrita da memória, tem projetado uma imagem sempre viva e atual do poeta.

Em 2015, quando começaram a sair, pela Editora da Universidade Federal do Pará, os primeiros volumes da refinada coleção Max Martins, poesia completa, com organização e projeto gráfico de Age de Carvalho, notei que aquele antigo acervo de fotos voltava a assumir uma nova configuração. Agora a figura do poeta não precisa aparecer de corpo inteiro, apenas fragmentos do seu rosto vão sendo sutilmente soletrados capa a capa. Quando a coleção chegar ao fim, disponibilizando individualmente todos os livros de Max Martins, a soma das fotos nos revelará um retrato mais completo da sua poesia. 
